\title{
Thermometric analysis of blood metabolites in ICU patients
}

\author{
Josefin Adlerberth $^{1} \cdot$ Qinglai Meng $^{2} \cdot$ Michael Mecklenburg $^{3} \cdot$ Zengmin Tian $^{4} \cdot$ Yikai Zhou $^{5} \cdot$ Leif Bülow $^{1} \cdot$ Bin Xie $^{1}$ (I)
}

Received: 5 December 2018 / Accepted: 28 September 2019 / Published online: 30 October 2019

(c) The Author(s) 2019

\begin{abstract}
Real-time monitoring of patient's blood metabolites, such as glucose and lactate, could potentially improve surgery and recovery outcomes for patients in surgical and intensive care units. Our enzyme thermometric biosensor which is based on flow injected calorimetric determination of immobilized enzyme reaction is capable of performing continuous, fast, and quantitative analysis of metabolites using whole blood. A key technical advantage the assay affords is the ability to use unpretreated whole blood. In this article, the enzyme thermometric biosensor was used, for the first time, to determine glucose and lactate concentrations in the blood of ICU patients. The linear detection range for glucose was $0.5-30 \mathrm{mM}$ and $0.25-12 \mathrm{mM}$ for lactate, using a $20 \mu \mathrm{L}$ sample volume. A maximum sampling rate of 15 measurements per hour was achieved using venous blood samples, which corresponds to a 4-min measurement interval. In order to validate the accuracy of the results, a comparative analysis between the thermometric biosensor and the clinically applied instrument (LifeScan's OneTouch ${ }^{\circledR}$ ) which is based on disposable dry chemical reaction was performed using samples from 33 patients. The results showed a good correlation between the two methods for both glucose $(r=0.843, p<0.0001)$ and lactate $(r=0.78, p=0.0105)$. The ability to monitor metabolite levels and trends on a clinically relevant timescale of $5 \mathrm{~min}$ is critical for intensive monitoring of ICP and operative patients.
\end{abstract}

Keywords Metabolite $\cdot$ Glucose $\cdot$ Lactate $\cdot$ Thermometric biosensor $\cdot$ Blood analysis

Josefin Adlerberth and Qinglai Meng have contributed equally to this work.

\section{Zengmin Tian}

tzmwjp@sina.cn

$\triangle$ Bin Xie

bin.xie@ tbiokem.lth.se

1 Pure and Applied Biochemistry, Department of Chemistry, Lund University, Naturvetarvägen 14, Box 124, 22100 Lund, Sweden

2 Institute of Biomedical Sciences, Shanxi University, Taiyuan, Shanxi Province, China

3 BT Biomedical Technology, 22738 Lund, Sweden

4 Department of Neurosurgery, Navy General Hospital, Beijing, China

5 Institute of Environmental Medicine, Tongji Medical College, Huazhong University of Science and Technology, Wuhan, China

\section{Introduction}

Metabolites in human blood can provide valuable information for profiling and assessing health status. For example, evaluation of patient's lactate can be useful in predicting septic shock and multi-organ dysfunction, whereas high glucose levels have been recognized as a risk factor for post-surgery infection. Rapid glucose and lactate monitoring is particularly important for management of critically ill and diabetic patients. In the management of stress-induced hyperglycemia, which is commonly observed in patients with or without diabetes in intensive care units (ICUs) [1], tight glucose control reportedly decreased morbidity or mortality or both in surgical, medical, and pediatric ICUs [2-4]. This is due to the fact that numerous drugs can alter laboratory test results and therefore can confuse the physician; for instance, spurious data from drug interference have been reported for glucose measurements [5]. On the other hand, classically, the attention of the anesthesiologist in managing the care of diabetic patients has centered around prevention of acute complications of abnormal blood glucose levels and ketosis during the surgery itself, but intraoperative glucose 
level management may influence perioperative events as diverse as wound healing, infection response, and neurological function [6]. With surgical stress, psychological or physical, the secretion of counter-regulatory hormones is increased; the same stress, together with the action of some anesthetic agents, may independently decrease insulin secretion in normal patients and type II diabetics [6].

Measurement of blood glucose concentration in ICUs is currently taken almost entirely intermittently, with analysis using either point-of-care glucose meters or blood gas analyzers [7]. Although accurate data are not available, most measurements are probably taken on glucose meters and the majority of samples are capillary blood obtained by finger pricks. The use of glucose meters and sampling capillary blood both have the potential to introduce errors into the measurement of blood glucose concentration [7]. The accuracy of glucose meters has been the subject of a number of studies, with the near-universal conclusion that they are not sufficiently accurate for use in the ICU [8-11]. Furthermore, many current meters are susceptible to interferences from reducing substances such as ascorbic acid and acetaminophen (paracetamol), and many are still affected by the patient's hematocrit $[12,13]$. An additional consideration is that the blood glucose concentration varies in different vascular beds and the site from which blood is sampled can introduce further errors. The blood glucose concentration for healthy person is in the range from 3.9 to $6.1 \mathrm{mM}$ in venous whole blood, but in radial arterial blood will be approximately $0.2 \mathrm{mmol} \mathrm{L}^{-1}$ higher than that in blood sampled from a peripheral vein, and 0.3 to $0.4 \mathrm{mmol} \mathrm{L}^{-1}$ higher than that in blood sampled from the superior vena cava. Sampling capillary blood in ICU patients, particularly in those who are hemodynamically unstable and being treated with vasopressors, can introduce large errors when compared with a reference method in which glucose is measured in central venous or arterial samples $[8,14]$. The frequency with which the blood glucose concentration is measured in the ICU makes venipuncture impractical, and viable alternatives are to sample from indwelling arterial or venous catheters [7].

Carefully monitoring the alterations of glucose and lactate could improve the outcome of patients. Therefore, the development of real-time monitoring system is of importance. Numerous techniques are available for continuous glucose monitoring in the ICU, including microdialysis and optical methods such as absorption spectroscopy, optical scattering, and fluorescence [15]. The blood glucose concentration can be measured in vivo by sensors that sit in the vascular or interstitial space or ex vivo by drawing blood samples or a dialysate to a sensor from an indwelling vascular catheter or dialysis membrane. Although these methods have some advantages, they require frequent recalibration and often suffer from electrical or optical interferences of the substrates, in particular in whole blood.
The enzyme thermometric (ET) biosensor is capable of detecting changes in temperature caused by an enzyme-catalyzed reaction [16-20]. The temperature change is proportional to the molar concentration of the substrate [21, 22]. Levels of glucose and lactate can be measured by immobilizing glucose or lactase oxidase, respectively. The ET has great potential at performing online and real-time monitoring in clinical environment since it has the ability to analyze whole blood without pre-treatment [23, 24]. An additional advantage is the capability of measuring multiple analytes simultaneously [25]. A previous small-scale study, analyzing glucose in blood from healthy donors and comparing the results obtained from ET instrument with a HemoCue glucose analyzer, has shown an excellent correlation [26]. However, the ET biosensor accuracy and feasibility of the glucose and lactate measurements in patient's blood in clinical environment have not been investigated. This article presents our novel studies in clinical assessment of the ET biosensor in comparison with the clinically applied instrument LifeScan OneTouch ${ }^{\circledR}$ in neurosurgical ICU in Navy General Hospital in Beijing. Whole blood glucose and lactate samples from more than 33 patients were analyzed and compared with the clinical results.

\section{Materials and methods}

\section{Chemicals and equipment}

Spherical controlled pore glass (CPG) beads with particle size of 100-160 $\mu \mathrm{m}$ and a mean pore diameter of $50 \mathrm{~nm}$ were purchased from VEB Trisola, Steinach, Germany. Glucose oxidase (E.C. 1.1.3.4) from Aspergillus niger (type X-S, 100-250 $\mathrm{U} \mathrm{mg}^{-1}$ ), lactate oxidase (E.C. 1.1.3.2) from Pediococcus sp., and catalase (E.C. 1.11.1.6) from bovine liver (2000-5000 $\mathrm{U} \mathrm{mg}^{-1}$ solid) were obtained from Sigma-Aldrich. The enzyme thermometric biosensor (Model ET-2010-2) used in this study was provided from Omik Bioscience AB, Sweden. A peristaltic pump (Type BT100N) was purchased from Baoding Shenchen Precision Pump Co., Ltd, China. An injection valve (Model V-450) was obtained from Upchurch Scientific, IDEX Co., Oak Harbor, USA. The D-(+)-glucose, L-lactic acid, and ethanolamine were also obtained from Sigma-Aldrich.

EDTA-K2 (Insepack, ST520EK) (EDTA-ethylene diamine tetra acetic acid) and sodium heparin (Insepack, ST750SH) tubes were purchased from Sekisui Medical technology (China) LTD. The clinical analyzer LifeScan OneTouch ${ }^{\circledR}$ instrument used in hospital was obtained from Johnson \& Johnson. All the solutions were preparing using de-ionized (18 M $\Omega$ ) water from a Milli-Q system (Millipore, Bedford, MA, USA). 


\section{Preparation of immobilized enzymes}

CPG beads were used as support material for immobilization of the enzymes. To $500 \mathrm{mg}$ of CPG was added $12 \mathrm{~mL}$ of $2.5 \%$ glutaraldehyde solution in $0.1 \mathrm{M}$ sodium phosphate buffer, adjusted to $\mathrm{pH}$ 7.0. The reaction was allowed to take place under reduced pressure for $30 \mathrm{~min}$ in order to allow air bubbles to exit. After an additional 30 min of incubation in atmospheric pressure, the brick red-colored product was washed exhaustively under reduced pressure with the phosphate buffer.

\section{Immobilizing glucose oxidase}

Glucose oxidase (GOD) and catalase (CAT) were co-immobilized in order to eliminate harmful $\mathrm{H}_{2} \mathrm{O}_{2}$. One gram of activated glass beads was transferred to 1000 units of glucose oxidase and 1000 units of catalase in $1.5 \mathrm{~mL}$ of $0.1 \mathrm{M}$ potassium phosphate buffer, $\mathrm{pH} 7$. Coupling was allowed to proceed overnight at $4{ }^{\circ} \mathrm{C}$ and under mild agitation. In the following day, the CPG was washed under reduced pressure with buffer before the remaining activated groups were blocked with ethanolamine $0.2 \mathrm{M}$ in buffer. After one hour gentle mixing at $4{ }^{\circ} \mathrm{C}$, the enzyme coupled CPG was exhaustively washed and loaded into the enzyme column $(0.4 \mathrm{~mL}$ volume). The unused columns were stored in buffer at $4{ }^{\circ} \mathrm{C}$.

\section{Immobilizing lactate oxidase}

Lactate oxidase (LOD) was immobilized according to the procedure described above for glucose oxidase immobilization. To $300 \mathrm{mg}$ activated GPG, 100 units of LOD were added.

\section{Performance method}

The enzyme thermometric biosensors utilize the absorption or production of heat in a reaction, reflected as a change in temperature within the reaction medium [27]. For non-specific interferences, e.g., in blood, a differential measurement method was performed using a split-flow system, one for the enzyme column and the other for the reference column. Therefore, the non-specific disturbance could be eliminated (Fig. 1). This is one of the advantages in real sample (e.g., blood) analysis.

\section{Assay schemes}

A sample volume of $20 \mu \mathrm{L}$ and a flow rate of $1.2 \mathrm{~mL} \mathrm{~min}^{-1}$ were used in this study unless stated elsewise. $0.05 \mathrm{mM}$ PBS (phosphate-buffered saline) was used as running buffer. For blood analysis, $2 \%$ heparin was also added to the running buffer to prevent coagulation.

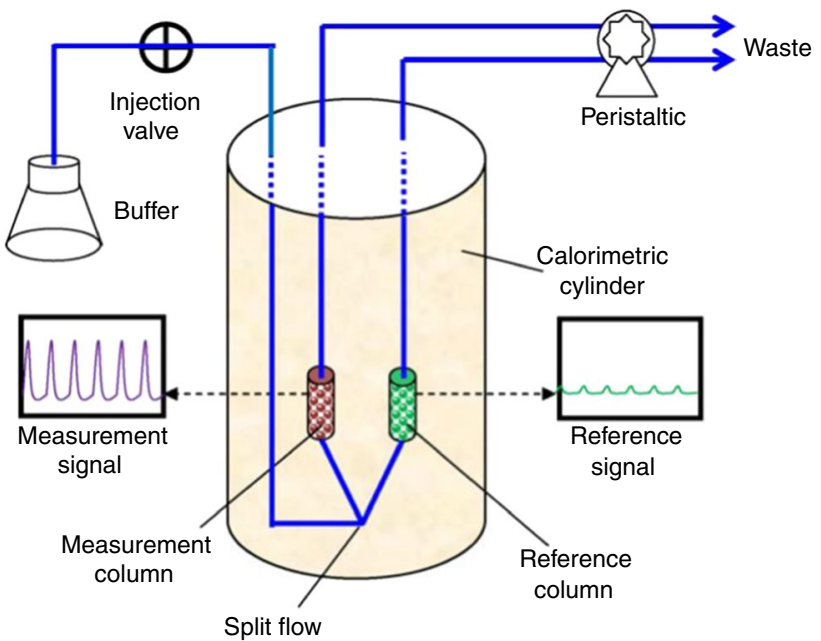

Fig. 1 Schematic setup of the ET biosensor for whole blood analysis

Patient blood samples got clinical permission and collected by clinical doctors. The samples were collected from veins into EDTA-K2 (Insepack, ST520EK) test tubes or sodium heparin (Insepack, ST750SH) tubes containing $20 \mathrm{mg} \mathrm{mL}^{-1}$ blood $\mathrm{NaF}$ (sodium fluoride). For comparative analysis, each blood sample was immediately divided into two aliquots: one for the clinical reference analysis by LifeScan OneTouch ${ }^{\circledR}$ instrument, and the other for the thermometric analysis. Samples were stored at $4{ }^{\circ} \mathrm{C}$ prior to use.

Addition of $\mathrm{NaF}$ in test tubes can be of importance if measurements are not taken immediately after withdrawing the blood samples since the glucose concentration rapidly decreases due to glycolysis [28]. As the effect on rate of glycolysis is limited during the first $1-2 \mathrm{~h}$, the alternative methods, such as acidification of blood and addition of EDTA, were suggested [29]. For lactate, as the concentration increased as high as $0.36 \mathrm{mM}$ during the first $30 \mathrm{~min}$ after the acquisition [30], adding NaF could stabilize the concentration.

The thermometric biosensor measurements run continuously in the interval of every 5-min injection of samples. In calibration, blood samples spiked with defined substrate of $1 \mathrm{mM}$ in buffer were prepared for control.

\section{Statistical analysis}

Statistical analyses were performed with Prism 5.0 (GraphPad Software Inc, San Diego, CA, USA). Unpaired Student's t-test was used to compare differences, and a two-tailed $p$ value less than 0.05 was considered significant. The deviation of the ET data versus the clinical data was represented as the mean deviation \pm standard deviation. Spearman's correlation coefficient $r$ was used to determine the correlation between variables. 


\section{Results}

\section{Assay optimization}

By adding 2\% heparin to the running buffer, blood cells were less extent trapped inside the column and the response baseline became more stable. 5\% Heparin addition was also investigated, but did not result in any additional improvement. During the following experiments, $2 \%$ heparin was used in running buffer.

In comparison with EDTA-K2 containing samples, more stable responses from analysis of the sodium heparin containing samples were obtained. However, since the glucose concentration rapidly decreased using the heparin tubes, an addition of $\mathrm{NaF}$ was required.

\section{Linear range and calibration}

In order to analyze glucose and lactate in patients including diabetes, a sufficient measurement range of the glucose and lactate concentration should be investigated with ET biosensor, since blood glucose concentration of diabetic patient can be more than $20 \mathrm{mM}$, and lactate level can be elevated from normal 1.15 to $10 \mathrm{mM}$ for some patients, e.g., cardiac disease [31]. A series of concentrations of glucose and lactate in buffer were determined with ET instrument. The linear ranges $0.5-30 \mathrm{mM}$ for glucose and $0.25-12 \mathrm{mM}$ for lactate were achieved (Fig. 2). The linear regression coefficients were 18.4 and 9.5 for glucose and lactate, respectively.

For recalibration of standard concentration in buffer and whole blood, blood samples spiked with a defined concentration of substrate (1 $\mathrm{mM}$ in buffer) were tested. Blood spiked with substrate gave incorrect result since the substrate was instantly consumed. This is studied by the following experiments.

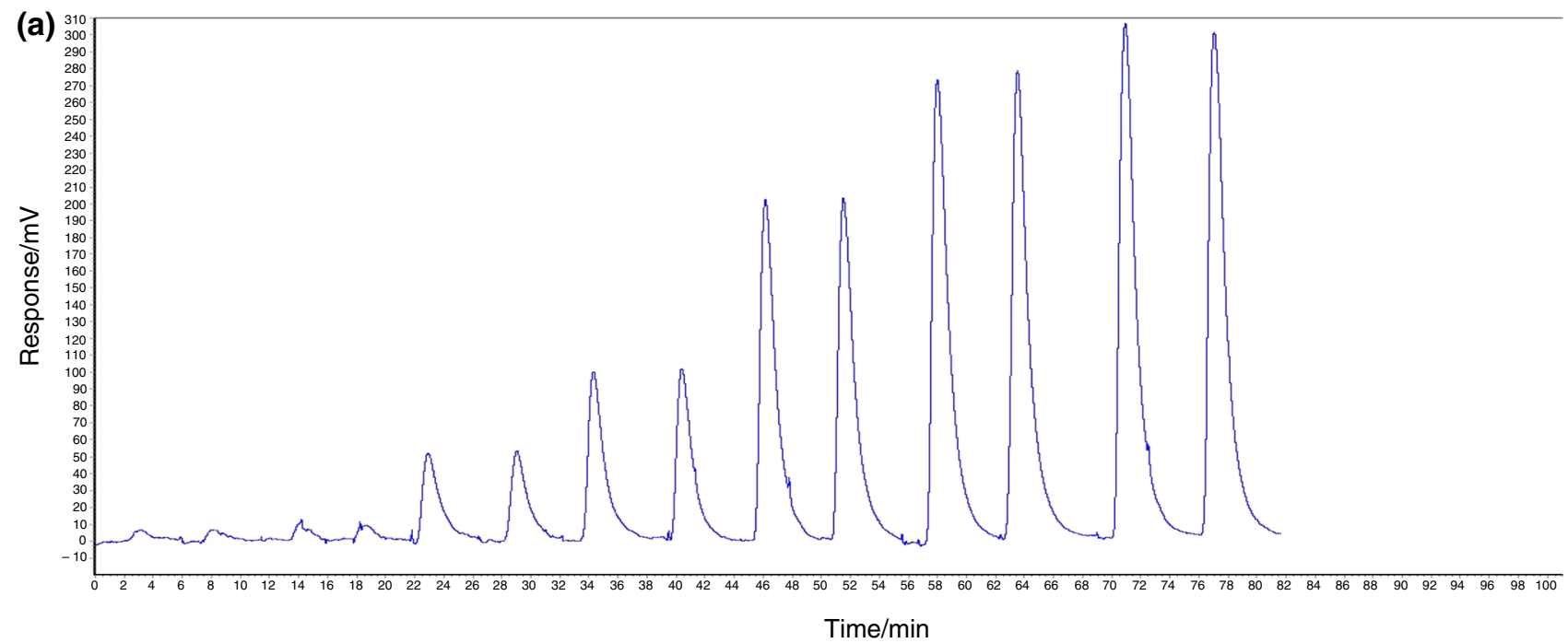

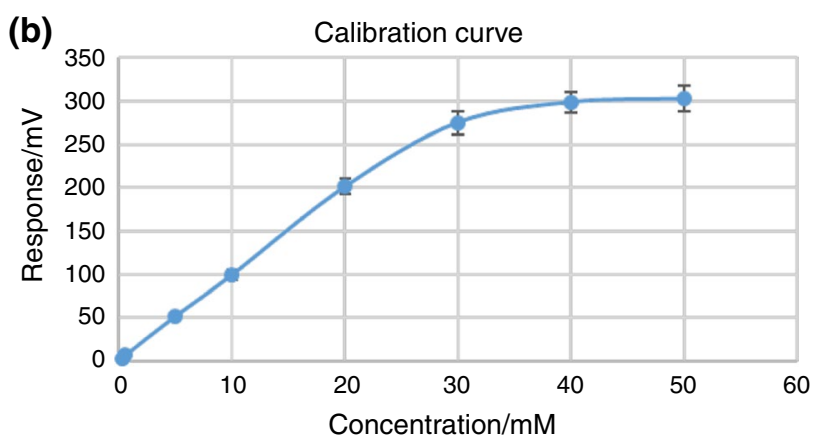

Fig. 2 ET measuremental linear range of glucose and lactate in buffer. a Real responses to a series of glucose concentration $0.5,1.0$, $5.0,10.0,20.0,30.0,40 \mathrm{mM}$. Calibration diagrams of the linear range

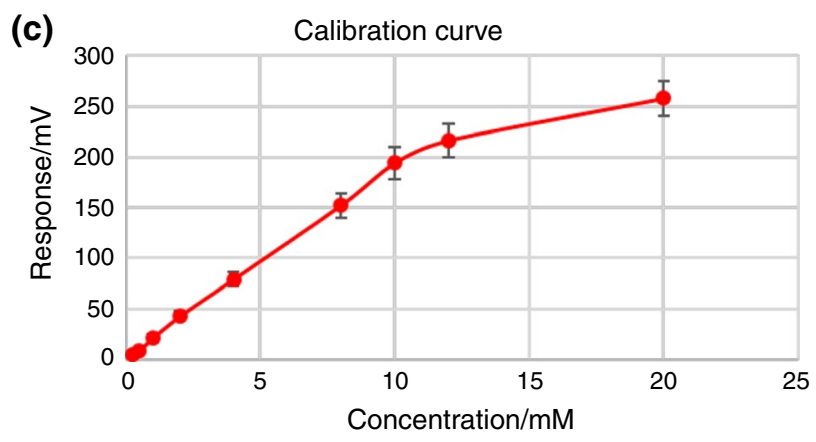

for glucose and lactate are shown in $\mathbf{b}$ and $\mathbf{c}$, respectively. Glucose and lactate concentrations $0.5-50 \mathrm{mM}$ and $0.25-20 \mathrm{mM}$ were analyzed, respectively 


\section{Glucose measurements}

\section{EDTA-K2 test tubes}

Even though analysis utilizing EDTA-K2 tubes was problematic, in optimized working conditions and using fresh blood samples, only a minor deviation $(4.63 \% \pm 5.90 \%$, mean $\pm \mathrm{SD}$ ) between the ET data versus the clinical data was observed (Fig. 3 and Table 1) and the ET data were well correlated with clinical data based on 16 patient's samples ( $r=0.8427, p<0.0001$, data not shown). The concentrations were recalibrated using a clinical data as reference from the day of analysis. The detailed data and patient's

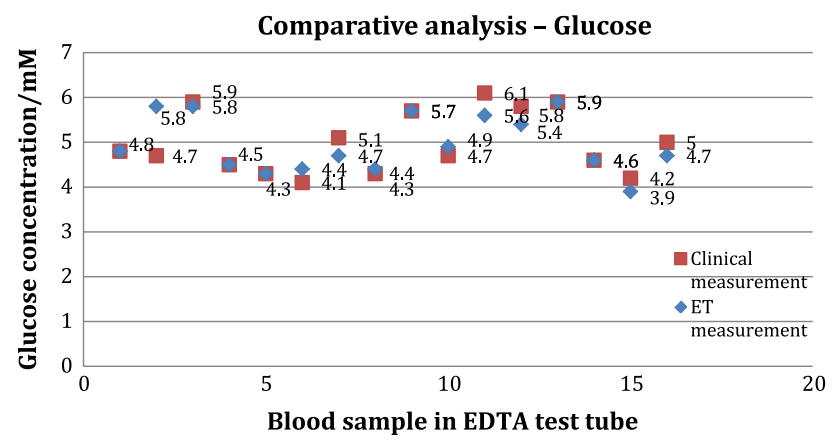

Fig. 3 Comparison between glucose concentrations obtained with the ET biosensor and the clinical analysis. Blood was withdrawn from patients into EDTA-K2 tubes information can be seen in Table 1. Out of 16 samples were 15 within $\pm 10 \%$ deviation from clinical results. Samples 1, 5,10 , and 14 were used as the calibration references.

\section{Heparin test tubes}

When EDTA tubes were substituted with sodium heparin tubes, more than 25 injections could be continuously determined with satisfied performance of ET. Disadvantage with these tubes was that the ET results for glucose measurements showed lower values and a high deviation $(40.6 \% \pm 9.37 \%)$ (mean $\pm \mathrm{SD}$ ) in comparison with the clinical results (Fig. 4), assuming that the blood glucose was constantly metabolized during the analysis process.

As blood glucose in the heparin tubes seemed to be decreased more rapidly than in EDTA tubes, a study by adding $20 \mathrm{mg} \mathrm{NaF} \mathrm{mL}^{-1}$ blood was investigated based on above conditions. Additional NaF significantly reduces deviation between ET data and clinical data down to $6.14 \% \pm 5.96 \%$ (mean $\pm \mathrm{SD})(p=0.0025$, data not shown) (Fig. 5 and Table 2). No significant decrease in the enzyme activity was observed after two days of operation.

\section{Reproducibility}

Even though the ET for analysis of 100 healthy human blood samples gave relative standard deviation value $10.5 \%$ [26], the reproducibility for analysis of patient

Table 1 Comparative data of ET with clinical analysis for patient blood glucose using EDTA-K2 test tubes

\begin{tabular}{|c|c|c|c|c|c|c|c|c|c|}
\hline Patient & Gender & Age & Disease & $C_{1} / \mathrm{mM}$ & $C_{2} / \mathrm{mM}$ & $\begin{array}{l}\text { Clinical } \\
\text { result/ } \\
\mathrm{mM}\end{array}$ & Dev./\% & $\begin{array}{l}\text { Mean dev. }(\%) \text { of the ET } \\
\text { versus the clinical }\end{array}$ & $\begin{array}{l}\text { Standard dev. (\%) of the ET } \\
\text { versus the clinical }\end{array}$ \\
\hline 1 & M & 62 & Craniopharyngoioma & 5.1 & 4.8 & 4.8 & 0 & 4.63 & 5.9 \\
\hline 2 & $\mathrm{~F}$ & 25 & Epilepsy & 6.2 & 5.8 & 4.7 & +23 & & \\
\hline 3 & M & 49 & Intracranial tumor & 6.3 & 5.8 & 5.9 & -2 & & \\
\hline 4 & M & 42 & Pituitary tumor & 4.8 & 4.5 & 4.5 & 0 & & \\
\hline 5 & M & 18 & Intracranial tumor & 6.6 & 4.3 & 4.3 & 0 & & \\
\hline 6 & M & 41 & Glioma & 6.8 & 4.4 & 4.1 & +7 & & \\
\hline 7 & M & 61 & Intracranial tumor & 7.3 & 4.7 & 5.1 & -8 & & \\
\hline 8 & M & 71 & Subdral effusion & 6.8 & 4.4 & 4.3 & +2 & & \\
\hline 9 & M & 21 & Craniopharyngoioma & 3.8 & 5.7 & 5.7 & 0 & & \\
\hline 10 & $\mathrm{~F}$ & 37 & Craniopharyngoioma & 3.3 & 4.9 & 4.7 & +4 & & \\
\hline 11 & M & 31 & Craniopharyngoioma & 3.8 & 5.6 & 6.1 & -8 & & \\
\hline 12 & M & 61 & Intracranial tumor & 3.6 & 5.4 & 5.8 & -7 & & \\
\hline 13 & M & 53 & Cerebellar tumor & - & 5.9 & 5.9 & 0 & & \\
\hline 14 & $\mathrm{~F}$ & 45 & Glioma & - & 4.6 & 4.6 & 0 & & \\
\hline 15 & M & 33 & Intracranial tumor & - & 3.9 & 4.2 & -7 & & \\
\hline 16 & M & 44 & Skull lack & - & 4.7 & 5.0 & -6 & & \\
\hline
\end{tabular}

Concentration $\left(C_{1}, C_{2}\right)$ where calibration with (1) blood samples supplemented with known concentration of glucose; (2) utilizing the clinical results from the day of analysis (in bold). The deviation (\%) between the ET data and the corresponding clinical data was calculated as (the concentration of $C_{2}$ divided by clinical results-1) $\times 100$ 


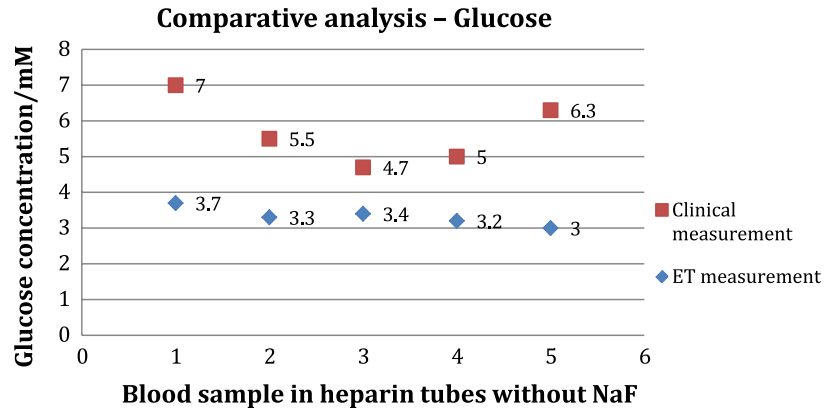

Fig. 4 Comparative analysis where ET instrument utilized heparin tubes without addition of $\mathrm{NaF}$ in blood samples. All ET measurements resulted in lower concentrations than that from the clinical analysis since blood glucose had rapidly been consumed

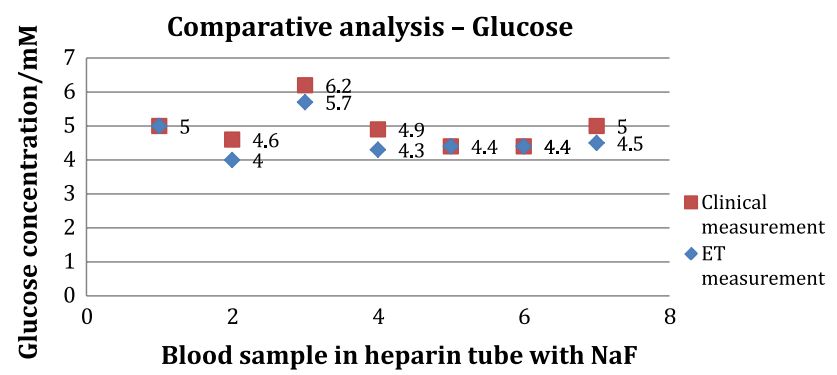

Fig. 5 Comparison between glucose concentrations obtained by the ET instrument and from clinical analysis. Blood was withdrawn into sodium heparin tubes for the ET measurement, and $20 \mathrm{mg} \mathrm{NaF} \mathrm{mL}^{-1}$ blood was immediately added. Out of the seven blood samples, were five within accepted accuracy range. Samples 1 and 6 were used as a calibration reference. All details can be seen in Table 2

blood samples was different. Continuous determination of patient blood glucose over 25 samples using heparin and $\mathrm{NaF}$ tubes gave standard deviation of $16.6 \%$. By comparison, the standard deviation value was worse for those samples without adding $\mathrm{NaF}$ in the tubes due to constant breakdown of the glucose. However, this could become better with ET for continuously in vivo monitoring of patient blood since the real-time analysis of fresh blood can minimize glucose variation. In the optimal conditions, the ET response time of $1.5 \mathrm{~min}$ and maximum sampling rate of 15 per hour were achieved for the blood analysis.

The deteriorated performance of ET for frequent determination of patient blood as compared with healthy body could be partly due to the fact that red blood cells (RBCs) in healthy body are biconcave discocyte with flexible membrane for elastic deformability that makes it easily to pass through small capillaries during microcirculation. Similarly, the healthy blood facilitates them to pass through the flow channel and enzyme column fitting with spherical CPG. However, pathological conditions affecting RBCs can lead to significant cell morphology changes, which compromises cell deformability and disrupt, and, in some instances, even obstruct blood circulation in human [32], that could be similar cause in the microfluidic channel of ET system.

\section{Lactate measurements}

In the consecutive three-day determinations, ten patient's blood lactate were evaluated with ET in comparison with the clinical results (Fig. 6), and an intermediate deviation between the ET data and the clinical data was $18.8 \% \pm 17.52 \%$ (mean \pm SD, Table 3$)$. However, a significant correlation between the data generated from two methods is still achieved ( $r=0.78, p=0.0105$, data not shown). Concentrations were calibrated using a clinical data as reference from the day of analysis. The details for data and patient information are listed in Table 3. It can be seen that the results obtained from these two methods present similar diagram pattern.

Table 2 Comparative data of ET with clinical analysis for patient blood glucose using sodium heparin test tubes

\begin{tabular}{|c|c|c|c|c|c|c|c|c|c|}
\hline Patient & Gender & Age & Disease & $C_{1} / \mathrm{mM}$ & $C_{2} / \mathrm{mM}$ & $\begin{array}{l}\text { Clinical } \\
\text { result/ } \\
\mathrm{mM}\end{array}$ & Dev. $/ \%$ & $\begin{array}{l}\text { Mean dev. \% of the ET } \\
\text { versus the clinical }\end{array}$ & $\begin{array}{l}\text { Standard dev. (\%) of the ET } \\
\text { versus the clinical }\end{array}$ \\
\hline 1 & $\mathrm{M}$ & 65 & Intracranial tumor & 4.1 & 5 & 5 & 0 & 6.14 & 5.97 \\
\hline 2 & M & 32 & Craniopharyngoioma & 3.2 & 4 & 4.6 & -13 & & \\
\hline 3 & $\mathrm{~F}$ & 34 & Glioma & - & 5.7 & 6.2 & -8 & & \\
\hline 4 & M & 54 & Epilepsy & 4.7 & 4.3 & 4.9 & -12 & & \\
\hline 5 & M & 45 & Intracranial tumor & 3.5 & 4.4 & 4.4 & 0 & & \\
\hline 6 & $\mathrm{~F}$ & 42 & Subdural effusion & - & 4.4 & 4.4 & 0 & & \\
\hline 7 & $\mathrm{~F}$ & 44 & Glioma & - & 4.5 & 5 & -10 & & \\
\hline
\end{tabular}

Concentration $\left(C_{1}, C_{2}\right)$ where calibration with (1) blood samples supplemented with known concentration of glucose and (2) utilizing the clinical results from the day of analysis (in bold) 


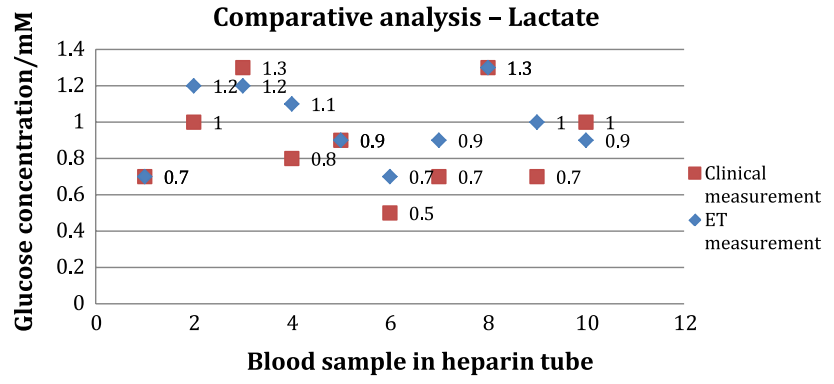

Fig. 6 Comparison of lactate concentrations obtained with ET instrument and clinical analysis. Blood was withdrawn into sodium heparin tubes from patient's vein. Out of the ten blood samples, were five within accepted accuracy range. Samples 1,5 , and 8 were used as a calibration references

\section{Discussion}

\section{Assay optimization}

Using EDTA-K2 test tubes, the coagulated blood could increase flow pressure inside the enzyme columns, which caused baseline shifting. However, by adding anticoagulant $2 \%$ heparin to the running buffer, the stability was improved. Similar procedure was performed with $5 \%$ heparin in buffer, but no further improvement could be seen, which means a $2 \%$ heparin buffer in some extend could be enough for anticoagulation of blood. In order to verify effect of the heparin on glucose oxidase activity, a study indicated that after one week operation of the ET instrument, no significant change for enzyme activity was observed.

\section{Linear range and calibration}

For the purpose of calibration, each day a blood sample was spiked with a defined concentration of substrate and $1 \mathrm{mM}$ substrate in buffer was analyzed. When adding glucose or lactate solution to the blood sample, it was partly consumed over period. The glucose was also seen to be consumed rapidly even though $\mathrm{NaF}$ addition perhaps the $\mathrm{NaF}$ function was delayed. Furthermore, response from substrate in buffer was higher than those from blood samples under same condition, probably as a consequence to the higher dispersion of blood samples in ET flow system. Utilizing these values for calibration resulted in either too high or too low concentrations. Instead, using one of the clinical data as reference made well correlation between ET and clinical methods. The calibrated linear ranges obtained for both glucose and lactate are adequate for clinical applications.

\section{Glucose measurements}

The comparative analysis between ET instrument and LifeScan OneTouch ${ }^{\circledR}$ utilizing EDTA and heparin test tubes showed good correlation $(r=0.843, p<0.0001)$. Acceptable deviation between the two assays was $\pm 10 \%$. Out of the 16 analyzed blood samples in EDTA tubes, 15 implemented this requirement. Many factors could affect the accuracy of glucose analysis; for instance, one slightly higher ET glucose value could be as a result of individual error, environmental, or substance interference. Metabolism rate and medication could also contribute the difference between patients, and exogenous substances interfering may contribute to the errors too. It is known that, for example, triglycerides and uric acid affect the results [33]. High levels of triglycerides cause low result since they take up volume and decrease the glucose in the capillary volume. Medication such as

Table 3 Comparative data of ET with clinical method for patient's blood lactate measurements using sodium heparin test tubes

\begin{tabular}{|c|c|c|c|c|c|c|c|c|c|}
\hline Patient & Gender & Age & Disease & $C_{1} / \mathrm{mM}$ & $C_{2} / \mathrm{mM}$ & $\begin{array}{l}\text { Clinical } \\
\text { result/ } \\
\mathrm{mM}\end{array}$ & Diff. $/ \%$ & $\begin{array}{l}\text { Mean dev. (\%) of the ET } \\
\text { versus the clinical }\end{array}$ & $\begin{array}{l}\text { Standard dev. (\%) of the ET } \\
\text { versus the clinical }\end{array}$ \\
\hline 1 & M & 45 & Epilepsy & 0.54 & 0.7 & 0.7 & 0 & 18.8 & 17.52 \\
\hline 2 & $\mathrm{~F}$ & 34 & Meningioma & 0.9 & 1.2 & 1 & +20 & & \\
\hline 3 & M & 23 & Craniopharyngoioma & 1 & 1.2 & 1.3 & -8 & & \\
\hline 4 & $\mathrm{~F}$ & 34 & Intracranial tumor & 0.9 & 1.1 & 0.8 & +38 & & \\
\hline 5 & M & 47 & Intracranial tumor & 1.7 & 0.9 & 0.9 & 0 & & \\
\hline 6 & M & 46 & Epilepsy & 1.3 & 0.7 & 0.5 & +40 & & \\
\hline 7 & M & 34 & Intracranial tumor & 1.7 & 0.9 & 0.7 & +29 & & \\
\hline 8 & M & 55 & Craniopharyngoioma & 1 & 1.3 & 1.3 & 0 & & \\
\hline 9 & $\mathrm{~F}$ & 45 & Meningioma & 0.8 & 1 & 0.7 & +43 & & \\
\hline 10 & M & 33 & Intracranial tumor & 0.7 & 0.9 & 1 & -10 & & \\
\hline
\end{tabular}

Concentration $\left(C_{1}, C_{2}\right)$ where calibration with (1) blood samples supplemented with known concentration of lactate and (2) utilizing the clinical results from the day of analysis (in bold) 
paracetamol, L-dopa (given to patients with Parkinson's), tolazamide, and ascorbic acid could also alter readings. The volume percentage of red blood cells, hematocrit, affects the result since the erythrocytes function as a physical barrier affecting diffusion rate of glucose and contain significant amounts of intracellular glucose. Clinical glucose meters are usually calibrated toward $40-50 \%$, which is the normal range for patients varying depending on age and gender. Hematocrit values increase during dehydration and occasionally for patients with lung diseases, or tumors result in a lower glucose reading during analysis.

For the blood samples withdrawn in heparin tubes with $\mathrm{NaF}$, five out of seven samples met the requirement except two results with deviation $-13 \%$. NaF was seen to be of great importance for glucose stabilization in blood as compared with the results of below $4 \mathrm{mM}$ glucose without addition of $\mathrm{NaF}$

\section{Lactate measurements}

The comparative analysis between ET instrument and LifeScan OneTouch ${ }^{\circledR}$ utilizing EDTA and heparin test tubes showed well correlation $(r=0.78, p=0.0105)$. However, the lactate concentration was seen to increase rapidly, making a big deviation for in vitro analysis. This could be due to the effects of leukocytosis or high hematocrit, in particularly, when the in vitro analysis was performed after $15 \mathrm{~min}$ of the sampling [34, 35]. For in vivo analysis, on the other hand, this will not be an issue as blood is directly withdrawn from patients.

\section{Conclusions}

The ET biosensor with split-flow channels has been validated in clinical site for comparative analysis of glucose and lactate in patient whole blood. Even though some performances need to be improved, the results from more than 33 patients demonstrated that the linear ranges for glucose and lactate could cover the clinical interest levels; the response time of $1.5 \mathrm{~min}$ and maximum sampling rate of 15 per hour were achieved for the blood analysis, which meets clinical measurement of frequency for intensive care patients at 5-min interval and could be applied for real-time monitoring of severe patients in the clinical condition.

Acknowledgements Open access funding provided by Lund University. This clinical study was performed at Beijing Navy General hospital according to cooperation between Wuhan Tongji Medical College, Beijing Navy General hospital, and Lund University. Swedish Research Council (VR 2009-5405), the Swedish Fund for Strategic Research (RBP14-0055), High-End Foreign Experts Project of Shanxi Province (SN20181400141), Fund Program for the Scientific Activities of Selected Returned Overseas Professionals in Shanxi Province (2018) and Shanxi "1331 Project" Collaborative Innovation Centre, 1331 CIC (206541001) are acknowledged for financial support of this work.

\section{Compliance with ethical standards}

Ethical approval All procedures performed in studies involving human participants were in accordance with the ethical standards of the institutional and/or national research committee and with the 1964 Helsinki Declaration and its later amendments or comparable ethical standards.

Informed consent Informed consent was obtained from all individual participants included in the study.

Open Access This article is distributed under the terms of the Creative Commons Attribution 4.0 International License (http://creativeco mmons.org/licenses/by/4.0/), which permits unrestricted use, distribution, and reproduction in any medium, provided you give appropriate credit to the original author(s) and the source, provide a link to the Creative Commons license, and indicate if changes were made.

\section{References}

1. Jacobi J, Bircher N, Krinsley J, Agus M, Braithwaite SS, Deutschman C, et al. Guidelines for the use of an insulin infusion for the management of hyperglycemia in critically ill patients. Crit Care Med. 2012;40:3251-76.

2. Van den Berghe G, Wouters P, Weekers F, Verwaest C, Bruyninckx F, Schetz M, et al. Intensive insulin therapy in critically ill patients. N Engl J Med. 2001;345:1359-67.

3. Van den Berghe G, Wilmer G, Hermans A, Meersseman W, Wouters PJ, Milants I, et al. Intensive insulin therapy in the medical ICU. N Engl J Med. 2006;354:449-61.

4. Vlasselaers D, Milants I, Desmet L, Wouters PJ, Vanhorebeek I, van den Heuvel I, et al. Intensive insulin therapy for patients in paediatric intensive care: a prospective, randomised controlled study. Lancet. 2009;373:547-56.

5. Palleschi G, Rahni MAN, Lubrano GJ, et al. A study of interferences in glucose measurement in blood by hydrogen peroxide based glucose probes. Anal Biochem. 1986;159:114-21.

6. Van Norman GA. Diabetes in the operating room: metabolic challenges for the anesthesiologist. J Crit Care. 1995;14:210-20.

7. Finfer S, Wernerman J, Preiser JC, Cass T, Desaive T, Hovorka R, et al. Clinical review: consensus recommendations on measurement of blood glucose and reporting glycemic control in critically ill adults. Crit Care. 2013;17:229-39.

8. Kanji S, Buffie J, Hutton B, Bunting PS, Singh A, McDonald K, Fergusson D, McIntyre LA, Hebert PC. Reliability of point-ofcare testing for glucose measurement in critically ill adults. Crit Care Med. 2005;33:2778-85.

9. Hoedemaekers CW, Klein Gunnewiek JM, Prinsen MA, Willems JL, Van der Hoeven JG. Accuracy of bedside glucose measurement from three glucometers in critically ill patients. Crit Care Med. 2008;36:3062-6.

10. Scott MG, Bruns DE, Boyd JC, Sacks DB. Tight glucose control in the intensive care unit: are glucose meters up to the task? Clin Chem. 2009;55:18-20.

11. Finkielman JD, Oyen LJ, Afessa B. Agreement between bedside blood and plasma glucose measurement in the ICU setting. Chest. 2005;127:1749-51.

12. Dungan K, Chapman J, Braithwaite SS, Buse J. Glucose measurement: confounding issues in setting targets for inpatient management. Diabetes Care. 2007;30:403-9. 
13. Lyon ME, Baskin LB, Braakman S, Presti S, Dubois J, Shirey T. Interference studies with two hospital-grade and two home-grade glucose meters. Diabetes Technol Ther. 2009;11:641-7.

14. Karon BS, Gandhi GY, Nuttall GA, Bryant Schaff HV, McMahon MM, Santrach PJ. Accuracy of Roche Accu-Chek inform whole blood capillary, arterial, and venous glucose values in patients receiving intensive intravenous insulin therapy after cardiac surgery. Am J Clin Pathol. 2007;127:919-26.

15. Oliver NS, Toumazou C, Cass AEG, Johnston DG. Glucose sensors: a review of current and emerging technology. Diabetic Med. 2009;26:197-210.

16. Chen Y, Andersson A, Mecklenburg M, Xie B, Zhou Y. Dual signal analysis eliminates requirement for milk sample pretreatment. Biosens Bioelectron. 2011;29:115-8.

17. Zhou S, Zhao Y, Mecklenburg M, Yang D, Xie B. A novel thermometric biosensor for fast surveillance of beta-lactamase activity in milk. Biosens Bioelectron. 2013;49:99-104.

18. Xie W, Bülow L, Xie B. Pyrroloquinoline quinone glucose dehydrogenase adopted in thermometric analysis for enhancement of glucose determination. J Therm Anal Calorim. 2018. https://doi. org/10.1007/s10973-018-7363-z.

19. Qie Z, Bai J, Xie B, Yuan L, Song N, Peng Y, Fan X, Zhou H, Chen F, Li S, Ning B, Gao Z. Sensitive detection of atrazine in tap water using TELISA. Analyst. 2015;140:5220-6.

20. Zhou Y, Liu Z, Yao N, Chen Y, Xie B. A novel biosensor based on an enzyme thermistor for sensitive measurement of chemical oxygen demand. Sensors. 2015;15:20501-10.

21. Xie B, Ramanathan K, Danielsson B. Mini/micro thermal biosensors and other related devices for biochemical/clinical analysis and monitoring. TrAC. 2000;19:340-9.

22. Xie B, Danielsson B. Thermal biosensor and microbiosensor techniques. In: Marks RS, Lowe CR, Cullen DC, Weetall HH, Karube I, editors. Handbook of biosensors and biochips. London: Wiley; 2007. p. 639-57.

23. Xie B, Harborn U, Mecklenburg M, Danielsson B. Clin Chem. 1994;40:2282-7.

24. Chen Q, Andersson A, Mecklenburg M, Xie B. Fast determination of antibiotics in whole blood. Clin Microbiol Infect. 2013;19:869-74.

25. Chen Q, Andersson A, Mecklenburg M, Xie B. A biosensing strategy for the rapid detection and classification of antibiotic resistance. Biosens Bioelectron. 2015;73:251-5.
26. Andersson A, Chen Q, Groop L, Bülow L, Xie B. Continuous and simultaneous determination of venous blood metabolites. Talanta. 2017;171:270-4.

27. Ramanathan K, Khayyami M, Danielsson B. Enzyme biosensors based on thermal transducer/thermistor. In: Mulchandani A, Rogers KR, editors. Enzyme and microbial biosensors, vol. 6. New York: Humana Press Inc; 1998. p. 175-86.

28. Burns DE, Knowler WC. Stabilization of glucose in blood samples: why it matters. Clin Chem. 2009;55:850-2.

29. Gambino R, Piscitelli J, Ackattupathil T, Theriault J, Andrin R, Sanfilippo M, Etienne M. Acidification of blood is superior to sodium fluoride alone as an inhibitor of glycolysis. Clin Chem. 2009;55:1019-21.

30. Seymour CW, Carlbom D, Cooke C, Watkins TR, Bulger EM, Rea TD, Baird GS. Temperature and time stability of whole blood lactate: implications for feasibility of pre-hospital measurement. BMC Res Notes. 2011;4:169-72.

31. Cocchi MN, Miller J, Hunziker S, et al. The association of lactate and vasopressor need for mortality prediction in survivors of cardiac arrest. Minerva Anestesiol. 2011;77:1063-71.

32. Diez-Silva M, Dao M, Han J, Lim CT, Suresh S. Shape and biomechanical characteristics of human red blood cells in health and disease. MRS Bull. 2010;35:382-8.

33. Barry H, Ginsberg MD. Factors affecting blood glucose monitoring: sources of errors in measurment. J Diabetes Sci Technol. 2009;3:903-13.

34. Astles R, Williams CP, Sedor F. Stability of plasma lactate in vitro in the presence of antiglycolytic agents. Clin Chem. 1994;40:1327-30.

35. Andersen O, Haugaard SB, Jorgensen LT, et al. Preanalytical handling of samples for measurement of plasma lactate in HIV patients. Scand J Clin Lab Invest. 2003;63:449-54.

Publisher's Note Springer Nature remains neutral with regard to jurisdictional claims in published maps and institutional affiliations. 